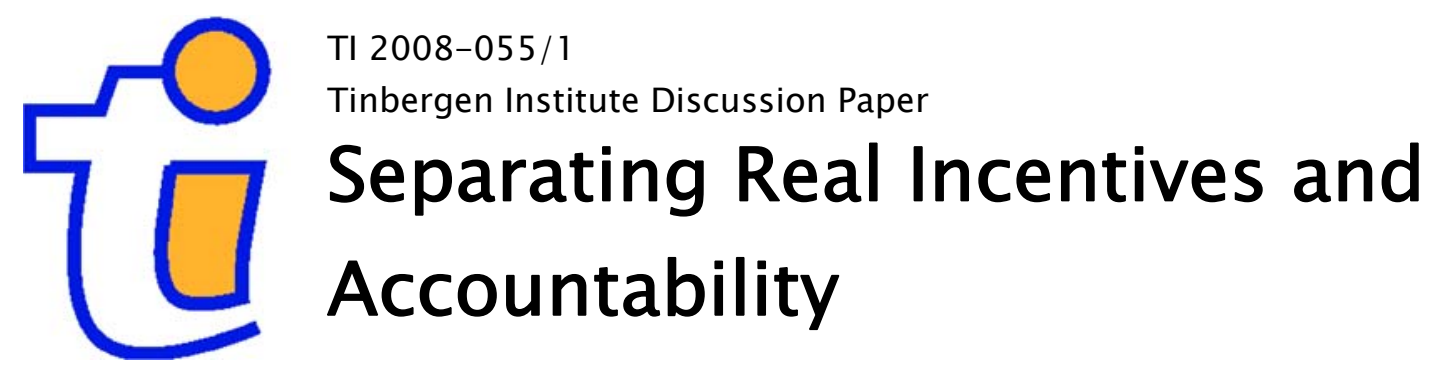

Ferdinand M. Vieider

Faculty of Economics, Erasmus University Rotterdam, and Tinbergen Institute. 


\section{Tinbergen Institute}

The Tinbergen Institute is the institute for economic research of the Erasmus Universiteit Rotterdam, Universiteit van Amsterdam, and Vrije Universiteit Amsterdam.

Tinbergen Institute Amsterdam

Roetersstraat 31

1018 WB Amsterdam

The Netherlands

Tel.: +31(0)205513500

Fax: $+31(0) 205513555$

Tinbergen Institute Rotterdam

Burg. Oudlaan 50

3062 PA Rotterdam

The Netherlands

Tel.: + $31(0) 104088900$

Fax: $+31(0) 104089031$

Most TI discussion papers can be downloaded at http://www.tinbergen.nl. 


\title{
Separating Real Incentives and Accountability
}

\author{
Ferdinand M. Vieider ${ }^{*}$ \\ Econometric Institute, Erasmus University Rotterdam
}

27 May 2008

\begin{abstract}
In experimental investigations of the effect of real incentives, accountability - the implicit or explicit expectation of a decision maker that she may have to justify her decisions in front of somebody else-is often confounded with the incentives themselves. This confounding of accountability with incentives makes causal attributions of any effects found problematic. We separate accountability and incentives, and find different effects. Accountability is found to reduce preference reversals between frames, for which incentives have no effect. Incentives on the other hand are found to reduce risk seeking for losses, where accountability has no effect. In a choice task between simple and compound events, accountability increases the preference for the simple event, while incentives have a weaker effect going in the opposite direction. It is thus shown that the confounding of accountability and incentives is relevant for studies on the effect of the latter, and that existing conclusions on the effect of incentives need to be reconsidered in light of this issue.

JEL classification: C91, D71, D81, Z13

Key words: Real v. hypothetical incentives; experimental economics; accountability; dual processing models; internal validity; simple and compound events; external validity; anchoring and adjustment; framing effects.

*Email: vieider@,few.eur.nl. I thank Peter P. Wakker and Philip E. Tetlock for helpful comments.
\end{abstract}




\section{Motivation}

Experimental economists have demonstrated the importance of real incentives for inducing cognitive effort in experimental tasks (Davis \& Holt, 1993; Harless \& Camerer, 1994; Harrison, 2007; Smith, 1982; Smith \& Walker, 1993), although the actual effect of incentives in different situations is sometimes still debated (Camerer \& Hogarth, 1999; Hertwig \& Ortmann, 2001; Loewenstein, 1999). Social influences on individual decisions studied in social psychology on the other hand have not received much attention from experimental economists, or from psychologists studying the effects of incentives. Accountability - the implicit or explicit expectation by a decision maker of having to justify her decisions in front of others-has however been found to influence numerous decision making processes (Lerner \& Tetlock, 1999).

When investigating the effects of incentives, accountability is often a confound. Hypothetical conditions provide for more anonymity than games that are actually played out in front of the experimenter, so that accountability is varied together with incentives in studies concerning the latter. An unaccountable hypothetical treatment is thus generally compared to a treatment in which outcomes are really paid out and in which accountability is high. While both accountability and real incentives usually trigger higher levels of attention towards the decision making process, confounding the effects of the two makes causal attributions problematic. It may thus be, in principle, that effects traditionally ascribed to real incentives are in fact due to accountability.

To investigate this issue, we separate accountability and incentive variations in typical experimental tasks. Studying choices between sure amounts and prospects framed as either gains or losses, we find accountability to reduce preference reversals between frames, whereas incentives do not affect the incidence of preference reversals. Incentives are however found to reduce risk seeking for losses, for which accountability shows no effect. In a choice task between simple and conjunctive prospects (Bar-Hillel, 1973), we find accountability to increase the frequency of choice for the simple prospects. Incentives on the other hand result in more frequent choices of the conjunctive prospects. When accountability and incentives are confounded, no significant effect is observed relative to the control treatment because the two effects cancel out. While the particular 
results obtained are specific to the tasks employed, these two examples illustrate the general desirability to disentangle real incentives and accountability.

The paper proceeds as follows. Section 2 discusses accountability and its effects. Section 3 presents evidence for the confounding of real incentives and accountability. In section 4 dual processing models are discussed as a possible interpretative framework. Section 5 presents the experiment and discusses results for the different tasks employed. Overall results and their implications are discussed in section 6. Section 7 concludes.

\section{Accountability}

A substantial literature in social psychology shows that accountability - the expectation by a decision maker that she may be called upon to justify her behavior in front of others — can substantially affect human decision making processes (Lerner \& Tetlock, 1999). Accountability in front of an audience with unknown views generally results in more cognitive effort. More options are considered in greater depth, thereby anticipating possible criticisms others might raise against one's choice, a phenomenon that has been called pre-emptive self-criticism (Tetlock, 1983; Tetlock \& Kim, 1987).

Accountability to an unknown audience has been found to lead to less biased decisions in cases where the normatively correct decision was either known by the subjects, or could be arrived at by higher cognitive effort (Simonson \& Nye, 1992). Accountability has thus been found among other things to reduce the fundamental attribution error (Tetlock, 1985), to improve coherence between gain and loss frames (Miller \& Fagley, 1991; Takemura, 1993; Takemura, 1994), and to reduce overconfidence (Arkes et al., 1987).

When on the other hand no solution is easily arrived at, people tend to choose the option that appears more easily justifiable (Simonson, 1989). This may be explained by the fact that people often rely on reasons when making choices (Shafir et al., 1993). In such cases, accountability has been shown to impair decisions e.g. for ambiguity aversion (Curley et al., 1986; Trautmann et al., 2008), for the dilution effect (Tetlock \& Boettger, 1989), and for the attraction and compromise effects (Simonson, 1989). 


\section{Separating Incentives from Accountability}

In investigations of the effects of real incentives, manipulations of incentives need to be clearly set apart from other external influences, in order to permit unequivocal causal attributions of any effect that may be observed. Unfortunately, many studies investigating the effects of real incentives on decisions co-vary accountability with incentives. The undetected manipulation of accountability in incentive studies may cast doubt on the results obtained, all the more so since it is not clear whether accountability might reinforce any potential effects of incentives or attenuate them. In other words, this co-variation implies a loss of control over the experimental conditions (Harrison, 1994; Smith, 1982).

Sometimes the confounding of accountability and incentives can be clearly deduced from the letter of the paper (e.g. in Epley \& Gilovich, 2005; Simmons et al., 2006; Wright \& Anderson, 1989). This covariation probably occurs for many more studies that vary incentives, and one may assume that it occurs in the majority of cases where it does not emerge clearly from the text that accountability variations have been controlled for. This suspicion is justified by the fact that controlling for accountability generally calls for special experimental procedures to be implemented-procedures that, if applied, could be reasonably expected to emerge from the description of the experimental method. Examples where such controls are implemented and can be deduced from the description of the experimental method are Wilson et al. (1996) and Wiseman \& Levin (1996).

\section{Dual Processing Theories: An Interpretative Framework}

Recent theorizing in psychology points in an interesting direction regarding mental processes. According to so-called dual processing theories (Chaiken \& Trope, 1999; Epstein, 2003; Evans, 2003; Kahneman, 2003a,b; Sloman, 2002) different mental processes may be activated in a given decision problem. An emotional or associative system that is located in an evolutionarily older part of the brain is activated together with a rational or rule-based system. The final decision will then result from the interaction of those two systems.

Dual processing theory assumes that different stimuli may activate different mental processes, which in turn may lead to different outcomes of a decision process. 
While incentives have generally been found to increase motivation and improve decision making (Davis \& Holt, 1993; Harless \& Camerer, 1994; Harrison, 2007; Smith, 1982; Smith \& Walker, 1993), there is some evidence that high monetary incentives may under certain circumstances trigger emotional reactions which activate the associative reasoning system (Camerer, 1992; Loewenstein et al., 2001; Rottenstreich \& Hsee, 2001). Accountability is thought to mostly activate rational mechanisms (Kirkpatrick \& Epstein, 1992; Scholten et al., 2007; Vieider, 2007). The latter may however not always result in better decisions being taken (Dijksterhuis, 2004; Simonson \& Nye, 1992; Wilson \& Schooler, 1991).

Additional evidence in favor of dual processing theories can be gathered from recent studies in neuroeconomics (Breiter et al., 2001; Fehr \& Camerer, 2007; Sanfey et al., 2006). Indeed, susceptibility to framing effects has been found to be associated with increased activity in parts of the brain that are associated with emotional processes (the amygdala), while decreased susceptibility to framing effects has been found to be associated with activity in parts of the brain thought responsible for rational processing (De Martino et al., 2006; McElroy \& Seta, 2003; McElroy \& Seta, 2004). Indications of an increased role of the amygdala in emotional reactions also come from the absence of skin conductance responses in patients whose amygdala is damaged (Bechara et al., 1999).

\section{Experiments}

\subsection{General Structure}

Two-sided non-parametric tests are used throughout, unless specified otherwise.

Subjects: 166 subjects were recruited from a list of volunteers at Erasmus University Rotterdam. The average age of the subjects was 21.8 years, and 58\% were male. All subjects were paid a flat fee of $€ 15$ (\$23) for their participation. No additional earning possibilities were mentioned in the recruitment process in order to avoid a possible selection bias into the real-incentive treatments. 
Treatments: The design is $2 \times 2$, with accountability and incentives varied in an orthogonal fashion. Subjects were divided as indicated in table 1:

Hypothetical

Unaccountable

Accountable

Table 1: Experimental Design

Treatments are designated by first letters of manipulations-UH: Unaccountable Hypothetical; AH:

Accountable Hypothetical, etc. Numbers of subjects are indicated in parentheses.

Accountability Manipulation: In the unaccountable treatment, subjects were told that their answers were confidential and could not be traced back to them. They were told that after the experiment they should put their completed questionnaire in a cardboard box by the exit of the room upon which they would be paid the flat fee of $€ 15$ for their participation. They would then either be dismissed or told to return to their seats, depending on the incentive manipulation (see below). Also, all sessions were held with groups of approximately 15 subjects, so as to reassure subjects that their answers could not be traced back to them.

In the accountable treatment subjects were told that upon completion of the task they would be asked to take their questionnaire with them to another room, where an experimenter would interview them about their choices. After the interview, subjects were paid the flat fee of $€ 15$ for their participation. They would then either be dismissed or told to return to their seats, depending on the incentive manipulation (see below).

Following conventions in the literature, and to be sure that subjects understood the instructions, a manipulation check was included at the end of the experimental questionnaire. Subjects in the high accountability treatments had a higher expectation than unaccountable subjects that they would have to justify their decisions $(Z=3.396$, $\mathrm{p}=0.0007$ ). Also, the time it took subjects to complete the questionnaire was measured. Although instructions for accountable and unaccountable subjects were of the same length, accountable subjects took on average almost 7 minutes more to complete the questionnaire $(\mathrm{Z}=5.839, \mathrm{p}=0.0000)$. 
Incentive manipulation: In hypothetical treatments subjects were paid the flat fee and dismissed once they had completed the questionnaire (and the interview in the accountable treatment). In the real incentives treatments they were told to return to their seats after they had been paid their participation fee (and after they had been interviewed in the accountable treatment).

Monetary incentives were implemented using a random incentive mechanism (Abdellaoui et al., 2007; Harrison et al., 2002; Holt \& Laury, 2002; Myagkov \& Plott, 1997). Its equivalence to a single and payoff relevant decision task has been empirically tested and confirmed (Hey \& Lee, 2005; Lee, 2008; Starmer \& Sugden, 1991). This manipulation did allow us to use high monetary incentives to test for potential emotional reactions. One out of five subjects was selected for real play, and then one of the tasks was randomly selected for real play. Some papers explicitly tested whether it matters if for each subject one choice is played for real or if this is done only for some randomly selected subjects and found no difference (Armantier, 2006; Harrison et al., 2007).

In order to be able to manipulate accountability, a careful procedure was implemented to assure subjects of their anonymity and to convince them that winnings could not be traced to them. This procedure was devised to avoid accountability in the real incentive unaccountable treatment. Also, the procedure was kept intact for the accountable and real incentives treatment in order not to introduce any confounds. Subjects detached a randomly generated four digit number from their questionnaires at the beginning of the experiment. Three numbers for each group of 15 were then randomly selected by the experimenter, so that winners would remain anonymous. The experimenter then played out the selected choice in front of the whole group. Prizes were finally put in envelopes with the corresponding number and handed to a secretary on a different floor, who was unrelated to both the subjects and the experimenter. Subjects could then pick up their winnings in a sealed envelope by presenting their number as soon as the experiment was over.

Tasks: Different tasks were selected to test the separate effects of accountability and incentives. These tasks are described next. 


\subsection{The Framing Effect}

\section{Introduction}

Different but normatively identical formulations of decision problems have consistently been found to influence choice patterns in a variety of situations. The most famous such situation is the Asian disease problem (Tversky \& Kahneman, 1981). Subject are asked to prepare for the outbreak of a new Asian flue from which 600 people are expected to die. In the gain formulation, they can choose between a) saving 200 people for sure, and b) a probability of $1 / 3$ of saving all 600 people, or else nobody. In the loss formulation a normatively equivalent choice is presented to them, only the two options are now presented as losses: a) 400 people will die for sure, and b) a 2/3 probability that all 600 people will die, or else nobody. While in the gain formulation the typical majority choice is the sure option $a$, in the loss formulation a majority of subjects typically chooses option $b$ (Kühberger, 1998).

The Asian disease problem as described has been shown to have a number of confounds that may reinforce the observed decision pattern. Similar results have however also been obtained with equally structured monetary prospects that avoid most of those issues. The latter furthermore have the advantage of permitting the use of real incentives.

\section{Method}

Task. A within subjects design is employed. Both gain and loss formulations were presented on the same page so as to encourage comparison of the two. Monetary prospects were employed to make incentives possible. Subjects could win €25 in expected value. The following choice pairs were proposed:

Positive Frame: $\quad$ You are now given a cash gift of $€ 20$. Those $€ 20$ are yours to dispose of. Additionally, you are given a choice between obtaining $€ 5$ for sure and playing a prospect with a $25 \%$ probability of winning $€ 20$ and a $75 \%$ probability of winning nothing.

Negative Frame: $\quad$ You are now given a cash gift of $€ 40$. Additionally, you are given a choice between giving up $€ 15$ for sure and playing a prospect with a $75 \%$ probability of losing $€ 20$ and a $25 \%$ probability of losing nothing. 


\section{Results}

Accountability reduced the incidence of preference reversals, and this holds true for both typical (sure amount in gain frame, prospect in loss frame) and opposite (prospect in gain frame, sure amount in loss frame) preference reversals (see table 2). The difference between accountable and unaccountable subjects overall (aggregated across incentive levels) is significant $(Z=2.04, p=0.041)$. The effect size found (Pearson's $\left.r=0.16^{1}\right)$ is similar to other effect sizes found for accountability on within subject framing (Takemura, 1993). Incentives on the other hand do not influence the incidence of preference reversals overall $(\mathrm{Z}=0.344, \mathrm{p}=0.732)$.

\begin{tabular}{lcc} 
& Hypothetical & Real Incentives \\
\hline Unaccountable & $24(56 \%)$ & $22(52 \%)$ \\
Accountable & {$[18,6]$} & {$[15,7]$} \\
& $17(40 \%)$ & $14(37 \%)$ \\
\hline
\end{tabular}

Table 2: Incentive and Accountability Influences on the Framing Effect

Numbers reported refer to overall number of preference reversals. Percentages refer to the percentage of subjects committing preference reversals. Numbers in square brackets represent typical reversals (sure amount in gain frame, prospect in loss frame), and opposite reversals (prospect in gain frame, sure amount in loss frame) according to the scheme: [typical/opposite].

Table 3 presents statistical comparisons treatment by treatment, which permit some additional insights into what is driving the results. Under hypothetical conditions, unaccountable subjects commit more preference reversals than accountable subjects, an effect that is marginally significant. A similar marginally significant result of accountability is obtained under real incentives. Incentives on the other hand are not found to affect preference reversals between frames.

\footnotetext{
${ }^{1}$ Pearson's $r$ is used as a measure of effect size throughout the paper. Effect sizes have the advantage to permit immediate comparison between findings from different studies independently of sample sizes or test statistics used, and thus facilitate comparison and integration of findings from different studies (Rosenthal, 1991). According to Cohen's (1988) classification, effect sizes of approximately $r=0.10$ can be seen as small, $\mathrm{r}=0.25$ as medium, and $\mathrm{r}=0.38$ as large, even though this scale should be used with caution.
} 


\begin{tabular}{|c|c|c|c|}
\hline Treatments & Statistics & Treatments & Statistics \\
\hline $\mathrm{UH}>\mathrm{AH}:$ & $\begin{array}{c}\mathrm{p}=0.066, \mathrm{Z}=1.502 \\
\mathrm{r}=0.16\end{array}$ & $\mathrm{AH}=\mathrm{UR}:$ & $\begin{array}{c}\mathrm{p}=0.119, \mathrm{Z}=-1.181 \\
\mathrm{r}=0.13\end{array}$ \\
\hline $\mathrm{UH}=\mathrm{UR}:$ & $\begin{array}{c}\mathrm{p}=0.377, \mathrm{Z}=0.316 \\
\mathrm{r}=0.03\end{array}$ & $\mathrm{AH}=\mathrm{AR}:$ & $\begin{array}{c}\mathrm{p}=0.403, \mathrm{Z}=0.247 \\
\mathrm{r}=0.03\end{array}$ \\
\hline $\mathrm{UH}>\mathrm{AR}:$ & $\begin{array}{c}\mathrm{p}=0.045, \mathrm{Z}=1.697 \\
\mathrm{r}=0.2\end{array}$ & UR > AR: & $\begin{array}{c}\mathrm{p}=0.083, \mathrm{Z}=1.386 \\
\mathrm{r}=0.16\end{array}$ \\
\hline
\end{tabular}

Table 3: Treatment by Treatment Comparison of Framing Effects

The inequality signs are used to indicate that there are more $(>)$ or fewer $(<)$ preference reversals in the first treatment than in the second; the equality sign $(=)$ stands for no statistically significant difference; p-values reported are all one-sided.

An interesting insight is gained by considering the gain and loss frame separately and treating them as between subject data. Overall, subjects were indifferent between the sure amount and the prospect in the gain frame ( $\mathrm{p}=0.938$, two-sided binomial test), but displayed a strong preference for the prospect in the loss frame $(\mathrm{p}=0.0000$, two-sided binomial test). For gains there is no main effect of either accountability $(\mathrm{Z}=-0.616$, $\mathrm{p}=0.54)$ or incentives $(\mathrm{Z}=0.708, \mathrm{p}=0.44)$. In the loss frame on the other hand, incentives have a strong effect $(\mathrm{Z}=3.607, \mathrm{p}=0.0003 ; \mathrm{r}=0.28)$. The effect of incentives goes in the direction of reducing risk seeking for losses. Indeed, while under hypothetical conditions risk seeking predominates ( $\mathrm{p}=0.0000$, two-sided binomial test), with real incentives risk neutrality cannot be rejected ( $\mathrm{p}=0.7376$, two-sided binomial test). There is no main effect of accountability in the loss frame $(\mathrm{Z}=1.203, \mathrm{p}=0.23)$. However there is an interaction effect, inasmuch as accountability reduces risk seeking under real incentives, an effect that is marginally significant $(\mathrm{Z}=1.760, \mathrm{p}=0.078)$. 


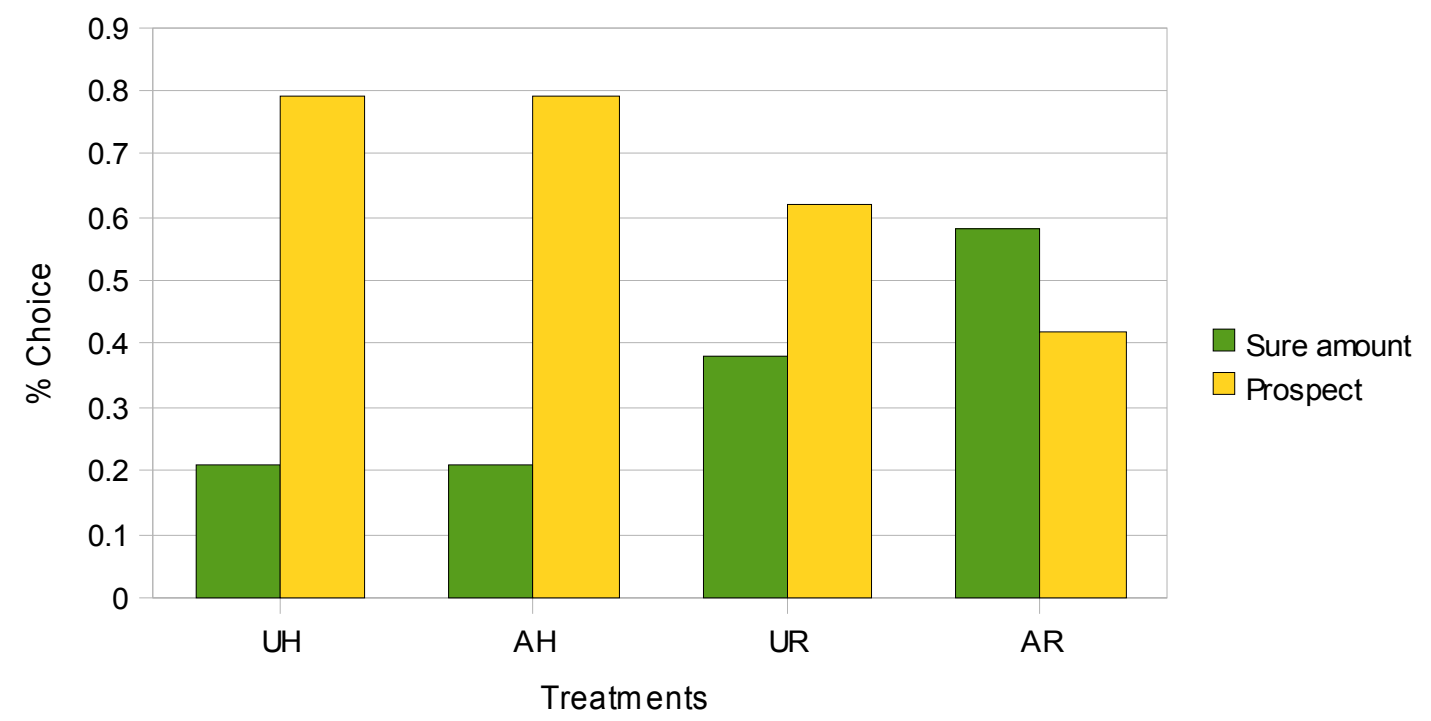

Figure 1: Preferences for the Sure Amount versus Prospect in the Loss Frame

\section{Discussion}

Accountability pressures improve the rationality of subjects and make them strive for coherence, thus leading to a significant reduction in preference reversals. Incentives on the other hand do not impact the incidence of preference reversals. These findings are consistent with some previous studies (Kühberger et al., 2002, Takemura, 1993). Since incentives per se do not have an effect on the occurrence of preference reversals between the frames, there are no interaction effects to speak of that one could study. However, if accountability should be varied together with incentives in an experimental test of the latter, there is a risk that any improvement in decision making found may be attributed to incentives instead of accountability, as can be seen from the comparison of the UH and AR treatments, where the effect is indeed strong.

The within subject design has the advantage that one can detect preference reversals proper, which provide a stronger test than between subject majority switches in frames. In the literature, however, between subjects tests of framing effects are more common (Kühberger, 1998). Treating the results as between subject data and testing bidirectional framing effects (Kühberger et al., 1999) - i.e.whether choice proportions in each frame differ from indifference between the two choices - another interesting picture emerges. Hypothetical treatments produce a pattern of risk neutrality for gains and risk 
seeking for losses. Incentives however have the effect of producing indifference between the sure amount and the prospect in the loss frame, while no effect is found for gains. Finally, there is an interaction effect-accountability is found to reduce risk seeking for losses under real incentives, while no such effect of accountability is found for hypothetical choice. This interaction effect would thus reinforce the effect of incentives if accountability and incentives should be confounded.

These results are generally consistent with previous findings in the literature. Accountability has been found to reduce framing effects for problems of this type, both for within subject designs (Takemura, 1993) and for between subject designs (Miller \& Fagley, 1991; Takemura, 1994; see also Sieck \& Yates, 1997). Framing effects have been found to persist under monetary incentives (Kühberger, 1998; Kühberger et al., 2002). The effect of incentives on choices in the loss frame that we found is consistent with the general evidence on strong effects of incentives in decisions involving losses (Cummings et al., 1995; Hogarth \& Einhorn, 1990; Horowitz \& McConnel, 2002; List \& Gallet, 2001). Unlike some of to the evidence on effects of incentives on risk attitude in the gain domain (Burke et al., 1996; Harrison, 1994; Kachelmeier \& Shehata, 1992; Slovic, 1969), no effects of incentives are found in the gain frame.

The connection between decreases in framing effects and the activation of rational processes is supported by findings on dual processing systems. McElroy \& Seta (2003) found that subjects with predominantly analytic/systematic thinking styles are less affected by framing than subjects with a predominantly heuristic/holistic thinking style. McElroy \& Seta (2004) found an association of increased preference reversals and activation of areas of the brain where holistic thought processes take place, while absence of preference reversals is associated with the activation of rational parts of the brain. DeMartino et al. (2006) found that decision switching for different frames is associated with increased activity of the amygdala, the part of the brain where emotional processes are supposed to be activated. Decreased susceptibility to framing effects is associated with increased activity in the prefrontal and orbital cortex, the part of the brain where rational processing is thought to take place. Evidence on different thinking styles also derives from Sunghan et al. (2005), who found that older adults are more affected by 
framing. Older adults have been known to rely more heavily on heuristic thinking than younger adults (Epstein, 2003; Johnson, 1990).

Beyond the interest of these findings for framing effects per se, the general message is to be found in the importance of keeping manipulations of accountability and incentives separate. Indeed, accountability appears to act as a motivational trigger for analytic thinking styles that increases the strive for coherence between the two frames. This conclusion is also supported by the finding that subjects take on average much longer to complete their decisions under accountability than when they are unaccountable. Incentives seem to rather focus attention on true preferences in the loss frame. If accountability is confounded with incentives, there is a risk that both effects may be attributed to the latter, a conclusion that is not warranted. Next we proceed to examining a decision problem in which such confounding may have even graver consequences.

\subsection{Choice between simple and compound events}

\section{Introduction}

People have been known to be affected by biases in the evaluation of probabilities of simple versus compound events (Bar-Hillel, 1973). A simple event such as drawing a red ball from an urn containing 50 red balls and 50 black balls to win a prize is compared to a conjunctive event such as drawing 7 red balls in succession with replacement from an urn containing 90 red balls and 10 black ones to win the same prize. The second, conjunctive, event is thereby generally preferred by a majority of subjects, even though it gives a probability of winning of .48 compared to the .5 of the simple event. When the same simple event is however compared to a disjunctive event, such as drawing at least one red ball in seven trials with replacement from an urn containing 10 red balls and 90 black balls, then the simple event is preferred by a majority of subjects, even though the disjunctive event has a higher probability of .52. It seems plausible that this bias in probability assessment is largely due to low cognitive effort, with the implication that accountability should lead to a more thorough assessment of probabilities and hence to a better final estimate. The potential effect of incentives is less clear. 


\section{Method}

Task. Six choice pairs of the kind proposed by Bar-Hillel (1973) were used, giving subjects a choice between a simple prospect involving one draw from an urn, and a conjunctive prospect involving repeated draws from an urn with replacement. The choice pairs were selected so that the overall probability of winning would always be lower in the conjunctive prospect than in the simple prospect. The conjunctive prospects used presented varying levels of calculation difficulties and were more or less close in probability to the simple prospect (see Appendix A).

Incentives. The choices involved can be played out in an incentive-compatible way. The prize for extracting a winning ball (or combination of balls) from the urn was $€ 20$.

Encoding. The choice was encoded as a dummy variable, with 0 indicating a choice of the (normatively superior) simple event, and 1 indicating a choice of the conjunctive event. These dummies where then summed for all six choice pairs to obtain a general index ranging from 0 to 6 . Figure 2 shows the occurrence of this index by treatment.

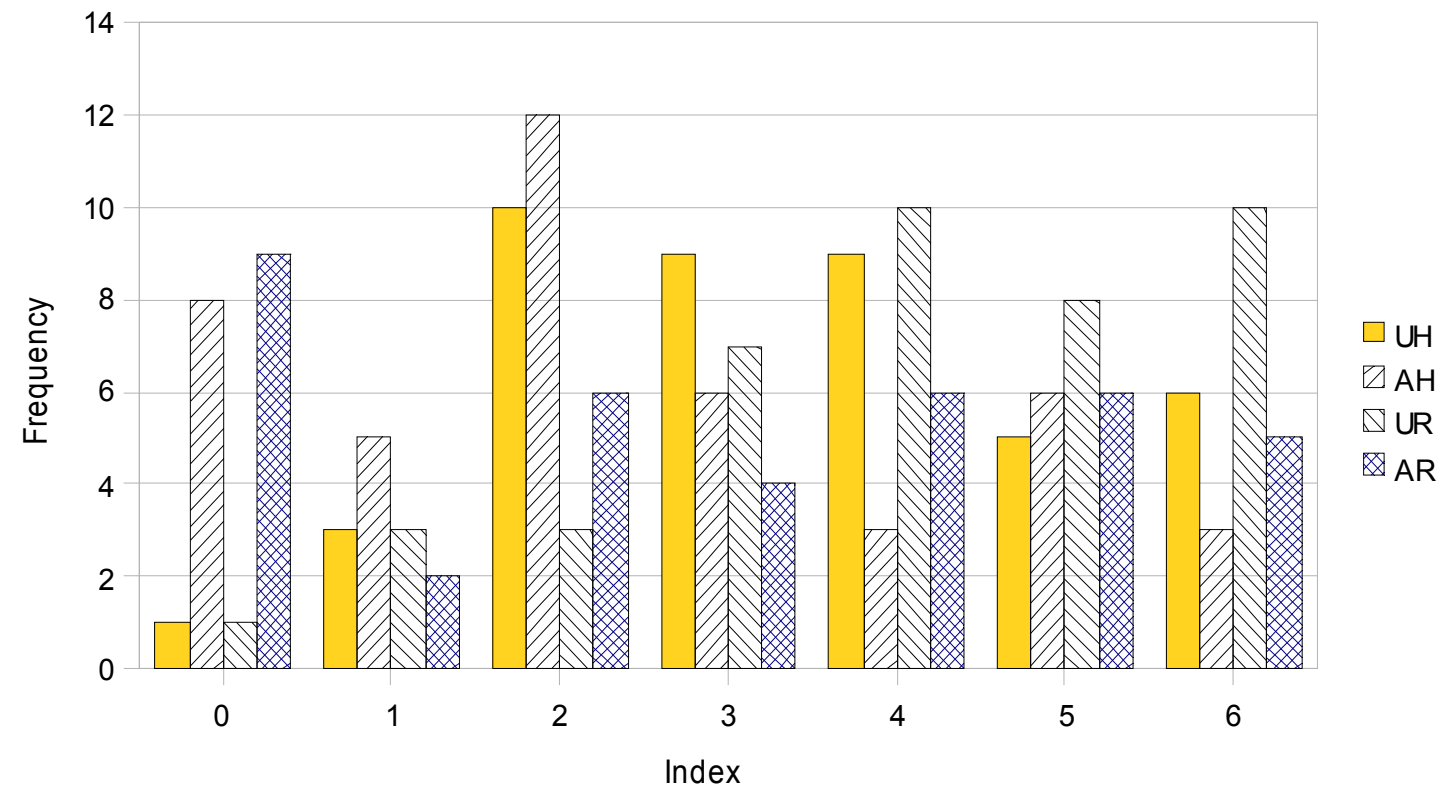

Figure 2: Frequency of Choice for the Conjunctive Prospect

The gray area indicates the control treatment UH. Upwards slashes ( / ) indicate accountability, downward slashes $(\backslash)$ real incentives. 


\section{Results}

Most subjects chose at least some conjunctive events. This was to be expected, as some probabilities were difficult to calculate and close to the ones of the simple prospects (see appendix A). Overall (aggregating across incentives), accountability significantly improves decisions, leading to more choices of the simple prospect $(Z=3.449, p=0.0006$; $\mathrm{r}=0.27)$. Incentives on the other hand are found to significantly impair decisions, leading to more choices of the conjunctive prospect $(\mathrm{Z}=2.018, \mathrm{p}=0.0436 ; \mathrm{r}=0.16)$, although the effect size is much smaller than for accountability. This can be seen also from figures $3 \mathrm{a}$ and $3 \mathrm{~b}$, which show the aggregated data for the accountability manipulation and the incentive manipulation. Remarkably, 17 accountable subjects consistently chose the superior simple event, as opposed to only 2 unaccountable subjects. Table 4 shows the average number of choices for the normatively inferior conjunctive prospect by treatment.

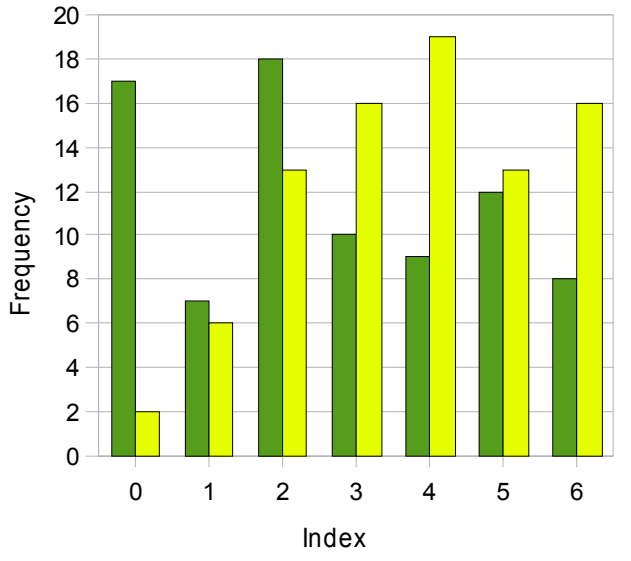

Figure 3a: Overall Effect of Accountability

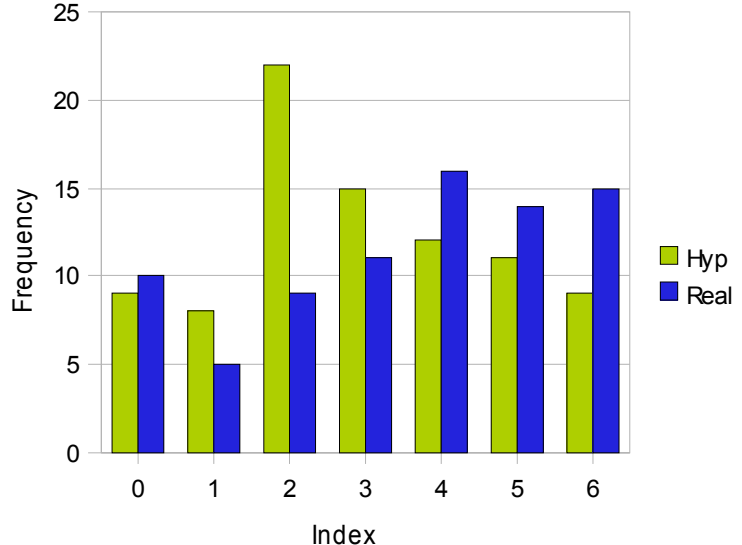

Figure 3b: Overall Effect of Incentives

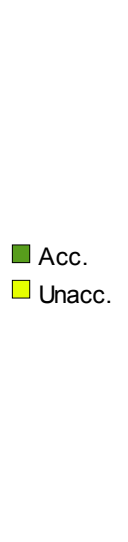

Hypothetical

\section{Unaccountable}

Accountable

Table 4: Incentive and Accountability Influences on Choices for Simple versus Conjunctive Events

Numbers reported refer to the index described above and represent the average number of conjunctive events chosen by subjects in each treatment. 
Some additional insights can be gained from the treatment by treatment comparison displayed in table 5. In the hypothetical treatments, accountability increases choices for the normatively superior simple prospects. This effect of accountability is replicated under real incentives. For unaccountable subjects, monetary incentives increase choices for the normatively inferior conjunctive prospects. This effect of incentives does however not carry over to accountable subjects, where the effect of incentives seems to be overwhelmed by the strong accountability effect. Since accountability and incentives produce effects in opposite directions, the strongest difference obtains between accountable subjects under hypothetical conditions and unaccountable subjects under real incentives. Passing from unaccountable hypothetical to real incentives under accountability on the other hand does not result in any significant difference as the two effects cancel out.

\begin{tabular}{|c|c|c|c|}
\hline Treatments & Statistics & Treatments & Statistics \\
\hline $\mathrm{UH}>\mathrm{AH}:$ & $\begin{array}{c}\mathrm{p}=0.007, \mathrm{Z}=2.451 \\
\mathrm{r}=0.26\end{array}$ & AH < UR: & $\begin{array}{c}\mathrm{p}=0.0001, \mathrm{Z}=-3.747 \\
\mathrm{r}=0.41\end{array}$ \\
\hline $\mathrm{UH}<$ UR: & $\begin{array}{c}\mathrm{p}=0.029, \mathrm{Z}=-1.898 \\
\mathrm{r}=0.21\end{array}$ & $\mathrm{AH}=\mathrm{AR}:$ & $\begin{array}{c}\mathrm{p}=0.19, \mathrm{Z}=-0.869 \\
\mathrm{r}=0.1\end{array}$ \\
\hline $\mathrm{UH}=\mathrm{AR}:$ & $\begin{array}{c}\mathrm{p}=0.15, \mathrm{Z}=1.030 \\
\mathrm{r}=0.11\end{array}$ & UR > AR: & $\begin{array}{c}\mathrm{p}=0.008, \mathrm{Z}=2.406 \\
\mathrm{r}=0.27\end{array}$ \\
\hline
\end{tabular}

Table 5: Treatment by Treatment Comparison of Choices for Simple versus Conjunctive Events The bigger or smaller signs are used to indicate that there are more $(>)$ or less $(<)$ choices for the conjunctive prospects in the first treatment than in the second; the equal sign $(=)$ stands for no statistically significant difference; $\mathrm{p}$-values reported are all one-sided.

\section{Discussion}

Accountability exerts a strong influence on decisions, increasing the frequency of choices for the superior simple prospect. Incentives on the other hand increase choices for the conjunctive prospect, although the effect is less strong than for accountability. Indeed, incentives produce an effect size of $r=0.16$ compared to the effect size of $r=0.27$ of accountability, and when both manipulations are combined the effect of accountability overwhelms the effect of incentives, as can be seen from the comparison of treatments $\mathrm{UH}$ and AR. Confounding accountability and incentives would thus lead to the conclusion that incentives have no effect, a conclusion that is not warranted based on the data presented. 
The bias in the evaluation of simple versus compound prospects observed has been attributed in the literature to an anchoring and adjustment process (Holtgraves \& Skeel, 1992; Kahneman \& Tversky, 1974; Kruglanski \& Freund, 1983). Subjects are thought to anchor their probability estimate for the conjunctive prospect at the probability of success in any single stage - thus $9 / 10$ of a red ball for conjunctive event and 1/10 for a red ball for disjunctive event in the example given in the introduction to the present section - and then fail to adjust these initial estimates to a sufficient degree. Anchoring and insufficient adjustment has been used to explain the conjunction fallacy (Tversky \& Kahneman, 2002), the fundamental attribution error (Tetlock, 1985), to model ambiguity aversion (Einhorn \& Hogarth, 1985; Hogarth \& Einhorn, 1990), and to explain scarce articulation of preferences (Slovic, 1995) and thus preference reversals (Tversky at al., 1988). Anchoring and adjustment has also been used to explain how people predict the preferences of their spouse (Davis et al., 1986), how consumers evaluate product bundles (Yadav, 1994), to criticize contingent valuation studies (Boyle et al., 1997; McCollum, 1997), for property pricing decisions (Northcraft \& Neale, 1987), for purchase quality decisions (Wansink et al., 1998), and for a host of other issues. The effects of accountability and incentives found may thus lead to differential predictions according to the measure in which the two elements affect the decisions involved.

Consistently with our findings, accountability has been found in the literature to increase adjustment away from an anchor, and thus to improve decision making (Kruglanski \& Freund, 1983). The evidence on the effects of incentives on the other hand is more mixed. The latter fact is partially due to the distinction between internally generated and externally given anchors in the literature (Epley \& Gilovich, 2001; Stack \& Mussweiler, 1997). This distinction has been based at least in part on the differential effect of incentives found for the two mechanisms (Chapman \& Johnson, 2002; Epley \& Gilovich, 2005). The distinction between internally generated and externally given anchors seems however to have been exaggerated (Simmons et al., 2006), and there are other reasons for the differential effects of incentives on anchoring found in the literature.

Indeed, most of the judgment tasks previously used in the anchoring and adjustment literature have the limitation that they cannot be incentivized in an incentivecompatible way. Only the best estimates in a group of people are typically rewarded, 
which may have led to strategic behavior of subjects. Also, the particular incentive structure employed has led to obvious covariation of accountability with incentives. For instance, Epley \& Gilovich (2005) vary accountability together with incentives while studying the effect of the latter on adjustment from an anchor. While subjects in the hypothetical condition remain anonymous, subjects in the incentive condition are asked to report their names and addresses on the experimental questionnaire so that they can be contacted - a manipulation that has been found to be sufficient by itself to generate accountability pressures (see e.g. Trautmann et al., 2008a, study 1). Similar problems also occur in Wright \& Anderson (1989) and Simmons et al. (2006).

If one compares the findings in this paper on the difference between treatments $\mathrm{UH}$ and AR to traditional findings in the literature that suffer from the confounding of accountability and incentives, the results are very similar. It emerges however clearly from the data presented above that this null result is due to the fact that the opposite effects of accountability and incentives cancel out. Taken separately, both accountability and incentives are shown to affect the decision making process.

For the particular choice task employed here, incentives are found to make decisions worse by increasing choices for the normatively inferior conjunctive events. Recent studies contain some indication that at least in some instances high monetary payoffs may trigger emotional reactions (Camerer, 1995; Loewenstein, 2000; Rottenstreich \& Hsee, 2001), and can thus lead to the activation of the experiential system. An indication in this direction is obtained by a marginally significant effect of age $(p=0.087)$, which is consistent with the finding that for adults the reliance on heuristic processing increases with age (Epstein, 2003; Johnson, 1990). A similar effect has been found by Kirkpatrick \& Epstein (1992), where the preference of subjects to bet on urns with larger absolute numbers of winning balls even when they offer inferior probabilities is reinforced by monetary incentives. More general implications of these findings are discussed next.

\section{General Discussion}

Beyond the importance of the present experimental findings for the literature on the decision biases involved, there is a more general lesson to be drawn. The results generally 
show the danger to experimentally confound accountability and incentives when trying to test the effect of the latter. Many existing studies on the effects of incentives have that confound.

One should note that the point of these findings is not to dispute the importance of real incentives in experiments. To the contrary, the results constitute a warning for scholars who try to generalize their hypothetical experimental results to the real world. Since monetary incentives are shown to often have effects on the decision making process, the absence of real incentives from experiments threatens to impact the external validity of such experiments. At the same time, there is a strong message for scholars who want to study the effect of incentives - if accountability is not controlled for in such experimental studies, then any effect that is found (or indeed, not found) cannot be attributed to the incentives themselves, but must rather be ascribed to the interaction between incentives and accountability. There is thus a problem of internal validity.

Accountability variations that have occurred in practice while studying incentives are likely to be weaker than the strong manipulation employed in the experiments of this paper. Indeed, the latter has been used with the purpose of proving a general point. However, the effects found for accountability are extremely strong, and it is known in the social psychology literature that even much weaker variations of accountability can produce sizable effects. Unless such variations are carefully controlled for, one can never be completely sure that monetary incentives - and not accountability variations, however small — are at the root of changes in behavior that have been observed.

The experimental controls implemented in this study to separate accountability from incentives are complicated. However, it does not appear necessary to implement such complicated measures for every investigation of real incentives. The most important lesson to be learned is that accountability should be kept constant between hypothetical and real incentive treatments in order to maintain control over the experimental conditions. The level of accountability at which this is done depends mostly on concerns of external validity, and may well be different according to the exact problem investigated. Keeping accountability constant could thus be achieved by playing out choices under both real incentives and hypothetical conditions, as done by Wiseman \& Levin (1996). While in the real incentive condition they actually played out choices and 
subjects were paid the resulting amount, in the hypothetical condition choices were still played out in front of the experimenter and outcomes were recorded on the instructions. Accountability was thus held constant across conditions. Another type of control was used by Wilson et al. (1996). They provided two tasks for both real and hypothetical incentives, one task in which they were truly interested and a filler task. While in one treatment the task of interest was played out, in the other treatment the filler task was played out.

The particular tasks employed may have led to especially strong effects of our manipulations. This is especially true for the choice tasks between simple and compound events, which have a clearly correct answer that can be calculated. Once again it is important to stress how effects of both accountability and incentives can occur for any kind of decision, and how their interaction can fundamentally undermine the finding of a study that co-varies both elements. Indeed, effects of accountability have been found also for problems where no "correct" answer exists (Huber \& Seiser, 2001; Ratner \& Kahn, 2002; Sedikides et al., 2002), and so have effects of incentives (Harrison, 2007; Slovic, 1969). In which cases one manipulation may have effects and the other one not, or the

effect of one manipulation may be overwhelmed by the effect of the other is an empirical question.

\section{Conclusion}

Traditional studies of monetary incentives are likely to have varied accountability together with monetary incentives, thus making clear causal attributions of any effects found (or not found) problematic. Conducting experiments in which accountability and monetary incentives are carefully kept apart we demonstrated the existence of such confounding effects. Mis-attributions of the effects of accountability to incentives are thus likely to have occurred in the literature. The message is thus that accountability needs to be carefully controlled for in studies of monetary incentives. Based on this evidence, the effects of real incentives may have to be reassessed using careful accountability controls. If accountability and monetary incentives are co-varied, we can only attribute any effect that may be found to the two phenomena jointly, but not to one or the other. 


\section{Appendix A: Choices between Simple and Compound Prospects}

Below 6 hypothetical problems are presented to you. Each one of them involves choosing between an option that involves one single extraction from a bag and one that involves multiple extractions from a different bag. In the multiple extraction option, the poker chip you have extracted will be placed back in the bag and the chips in the bag will be mixed before you extract again, so as to keep the composition of the bag constant. This holds true for all the problems below. Please pay attention however to both the composition of the bags and the number of extractions, which vary across problems. Your answers will be completely anonymous.

\section{Problem 1}

Imagine you were given a choice between two options to win €20. Option A involves extracting one chip from a bag containing 10 red and 10 green chips. If you extract a red chip, you win $€ 20$; if you extract a green chip, you win nothing. Option B involves extracting 7 chips in sequence with replacement from a bag containing 18 red chips and 2 green chips. If all 7 chips extracted are red you win $€ 20$; if one or more of the chips extracted are green, you win nothing. What would you choose?

Option A (extract 1 time from a bag with 10 red and 10 green chips, win if red)

Option B (extract 7 times from a bag with 18 red and 2 green chips, win if 7 times red)

\section{Problem 2}

Imagine you were given a choice between two options to win $€ 20$. Option A involves extracting one chip from a bag containing 5 red and 15 green chips. If you extract a red chip, you win $€ 20$; if you extract a green chip, you win nothing. Option B involves extracting 5 chips in sequence with replacement from a bag containing 15 red chips and 5 green chips. If all 5 chips extracted are red you win $€ 20$; if one or more of the chips extracted are green, you win nothing. What would you choose?

Option A (extract 1 time from a bag with 5 red and 15 green chips, win if red)

Option B (extract 5 times from a bag with 15 red and 5 green chips, win if 5 times red)

\section{Problem 3}

Imagine you were given a choice between two options to win $€ 20$. Option A involves extracting one chip from a bag containing 5 red and 15 green chips. If you extract a red chip, you win $€ 20$; if you extract a green chip, you win nothing. Option B involves extracting 7 chips in sequence with replacement from a bag containing 16 red chips and 4 green chips. If all 7 chips extracted are red you win $€ 20$; if one or more of the chips extracted are green, you win nothing. What would you choose?

Option A (extract 1 time from a bag with 5 red and 15 green chips, win if red)

Option B (extract 7 times from a bag with 16 red and 4 green chips, win if 7 times red) 


\section{Problem 4}

Imagine you were given a choice between two options to win $€ 20$. Option A involves extracting one chip from a bag containing 2 red and 18 green chips. If you extract a red chip, you win $€ 20$; if you extract a green chip, you win nothing. Option B involves extracting 4 chips in sequence with replacement from a bag containing 10 red chips and 10 green chips. If all 4 chips extracted are red you win $€ 20$; if one or more of the chips extracted are green, you win nothing. What would you choose?

Option A (extract 1 time from a bag with 2 red and 18 green chips, win if red)

Option B (extract 4 times from a bag with 10 red and 10 green chips, win if 4 times red)

\section{Problem 5}

Imagine you were given a choice between two options to win $€ 20$. Option A involves extracting one chip from a bag containing 4 red and 16 green chips. If you extract a red chip, you win $€ 20$; if you extract a green chip, you win nothing. Option B involves extracting 6 chips in sequence with replacement from a bag containing 15 red chips and 5 green chips. If all 6 chips extracted are red you win $€ 20$; if one or more of the chips extracted are green, you win nothing. What would you choose?

Option A (extract 1 time from a bag with 4 red and 16 green chips, win if red)

Option B (extract 6 times from a bag with 15 red and 5 green chips, win if 6 times red)

\section{Problem 6}

Imagine you were given a choice between two options to win $€ 20$. Option A involves extracting one chip from a bag containing 6 red and 14 green chips. If you extract a red chip, you win $€ 20$; if you extract a green chip, you win nothing. Option B involves extracting 2 chips in sequence with replacement from a bag containing 10 red chips and 10 green chips. If all 2 chips extracted are red you win $€ 20$; if one or more of the chips extracted are green, you win nothing. What would you choose?

Option A (extract 1 time from a bag with 6 red and 14 green chips, win if red)

Option B (extract 2 times from a bag with 10 red and 10 green chips, win if 2 times red) 


\section{References}

Abdellaoui, Mohammed, Aurélien Baillon, \& Peter P. Wakker (2007), "Combining Bayesian Beliefs and Willingness to Bet to Analyze Attitudes towards Uncertainty," Econometric Institute, Erasmus University, Rotterdam, the Netherlands.

Arkes, Hal R. (1991). “Costs and Benefits of Judgment Errors: Implications for Debiasing." Psychological Bulletin 10(3), 486-498.

Arkes, Hal R., and Peter Ayton (1999). "The Sunk Cost Effect and Concorde Effects: Are Humans Less Rational Than Animals?" Psychological Bulletin 125(5), 591-600.

Arkes, Hal R., Caryn Christensen, Cheryl Lai, and Catherine Blumer (1987). "Two Methods of Reducing Overconfidence." Organizational Behavior and Human Decision Processes 39, 133-144.

Arkes, Hal R., Robyn M. Dawes, and Caryn Christensen (1986). Factors Influencing the Use of a Decision Rule in a Probabilistic Task. Organizational Behavior and Human Decision Processes 37, 93-110.

Armantier, Olivier (2006), "Do Wealth Differences Affect Fairness Considerations," International Economic Review 47, 391-429.

Asch, Solomon E. (1955). “Opinions and social pressure.” Scientific American, 193, $31-35$.

Bar-Hillel, Maya (1973). "On the Subjective Probability of Compound Events."

Organizational Behavior and Human Performance 9, 296-409.

Baron, Jonathan (2000), “Thinking and Deciding.” Cambridge University Press, Cambridge, UK ( $3^{\text {rd }}$ ed.).

Baron, Jonathan and John C. Hershey (1988). "Outcome Bias in Decision Evaluation." Journal of Personality and Social Psychology 54(4), 569-579.

Bechara, Antoine, Hanna Damasio, Antonio R. Damasio, and Gregory P. Lee (1999). "Different Contributions of the Human Amygdala and Ventromedial Prefrontal Cortex to Decision-Making." Journal of Neuroscience 19(13), 5473-5481.

Beeler, Jasse D. and James E. Hunton (1997). “The Infuence of Compensation Method and Disclosure Level on Information Search Strategy and Escalation of Commitment." Journal of Behavioral Decision Making 10, 77-91. 
Boyle, Kevin J., F. Reed Johnson, and Daniel W. McCollum (1997). "Anchoring and Adjustment in Single-Bounded, Contingent-Valuation Questions." American Journal of Agricultural Economics 79(5), 1495-1500.

Breiter, Hans C., Itzhak Aharon, Daniel Kahneman, Anders Dale, and Peter Shizgal (2004). "Functional Imaging of Neural Responses to Expectancy and Experience of Monetary Gains and Losses." Neuron 30, 619 - 639.

Brockner, Joel (1992). "The Escalation of Commitment to a Failing Course of Action: Toward Theoretical Progress.” The Academy of Management Review 17(1), $39-61$.

Brown, Thomas C. (2005). "Loss Aversion Without the Endowment Effect, and Other Explanations for WTA-WTP Disparity." Journal of Economic Behavior and Organization 57, 367-379.

Burke, Michael S., John R. Carter, Robert D. Gominiak, and Daniel F. Ohl (1996). “An Experimental Note on the Allais Paradox and Monetary Incentives." Empirical Economics 21, 617-632.

Camerer, Colin F. (1989), “An Experimental Test of Several Generalized Utility Theories," Journal of Risk and Uncertainty 2, 61-104.

Camerer, Colin (1992). "Recent Tests of Generalizations of Expected Utility." In W. Edwards, ed., "Utility Theories: Measurements and Applications", 207-251, Boston: Kluwer.

Camerer, Colin F. (1995). "Individual Decision Making." In J. H. Kagel and A.E. Roth (Eds), “The Handbook of Experimental Economics", Princeton University Press. Camerer, Colin F. and Robin M. Hogarth (1999). "The Effects of Financial Incentives in Experiments: A Review and Capital-Labor-Production Framework." Journal of Risk and Uncertainty, 19(1), 7-42.

Chaiken, Shelly, and Yaacov Trope, Ed.s (1999). "Dual-Processing Theories in Social Psychology." New York: Guilford.

Cohen, J. (1988). "Statistical power analysis for the behavioral sciences (2nd ed.)." Hillsdale, NJ: Erlbaum

Cubitt, Robert P., Alistair Munro and Chris Starmer (2004). "Testing Explanations of Preference Reversal.” The Economic Journal 114, 709-726. 
Cummings, Robert G., Glenn W. Harrison, \& E. Elisabeth Rutström (1995), "Homegrown Values and Hypothetical Surveys: Is the Dichotomous Choice Approach Incentive-Compatible?" American Economic Review 85, 260-266.

Davis, D. D., and C. A. Holt (1993). "Experimental Economics.” Princeton University Press.

Davis, Harry L., Stephen J. Hoch, and E. K. Easton Ragsdale (1986). "An Anchoring and Adjustment Model of Spousal Predictions." Journal of Consumer Research 13.

Dawes, R. M. (1996). "The Purpose of Experiments: Ecological Validity Versus Comparing Hypotheses." Behavioral and Brain Sciences 19(20).

De Martino, Benedetto, Dharshan Kumaran, Ben Seymour, and Raymond J. Dolan (2006). "Frames, Biases, and Rational Decision-Making in the Human Brain." Science 313, 684-687.

Denes-Raj, Veronika, and Seymour Epstein (1994). „Conflict Between Intuitive and Rational Processing: When People Behave Against Their Better Judgment.” Journal of Personality and Social Psychology 66(5), 819-829.

Dijksterhuis, Ap (2004). "Think Different: The Merit of Unconscious Thought in Preference Development and Decision Making." Journal of Personality and Social Psychology 87(5), 586-598.

Dominowski, R.L. (1990). “Problem Solving and Metacognition.” In K.J. Gilhooly, M.T.G. Keane, R.H. Logie, and G. Erdos (eds.), "Lines of Thinking: Reflections on the Psychology of Thought: Vol. 2 Skills, Emotions, Creative Processes, Individual Differences, and Teaching Thinking." Chichester: Wiley.

Einhorn, Hillel J. and Robin M. Hogarth (1985). “Ambiguity and Uncertainty in Probabilistic Inference.” Psychological Review 92(4), 433-c461.

Epley, Nicholas and Thomas Gilovich (2004). “Are Adjustments Insufficient?" Personality and Social Psychology Bulletin 30(4), 447-460.

Epley, Nicholas and Thomas Gilovich (2005). "When Effortful Thinking Influences Judgmental Anchoring: Differential Effects of Forewarning and Incentives on Selfgenerated and Externally Provided Anchors." Journal of Behavioral Decision Making 18, 199-212. 
Epley, Nicholas and Thomas Gilovich (2006). "The Anchoring-and Adjustment Heuristic." Psychological Science 17(4), 311-318.

Epstein, Seymour (2003). “Cognitive-Experiential Self-Theory of Personality.” In Millon, T., and M. J. Lerner (Eds.), "Comprehensive Handbook of Psychology, Volume 5: Personality and Social Psychology", 159-184. Hoboken, NJ: Wiley and Sons.

Evans, Jonathan St. B. T. (2003). "In Two Minds: Dual-Process Accounts of Reasoning." Trends in Cognitive Science 7(10), 454-459.

Fehr, Ernst, and Colin F. Camerer (2007). "Social Neuroeconomics: The Neural Circuitry of Social Preferences." Trends in Cognitive Sciences 11(10)

Frey, Bruno S. (1997), "Not Just for the Money; An Economic Theory of Personal Motivation." Edward Elgar Publishing, Brookfield, US.

Friedman, Daniel, Kai Pommerenke, Rajan Lukose, Garrett Milam, and Bernardo A. Huberman (2007). „Searching for the Sunk Cost Fallacy.” Experimental Economics 10, 79-104.

Gneezy, Uri, and Aldo Rustichini (2000). "Pay Enough or Don't Pay at All.” Quarterly Journal of Economics, 791-810.

Grether, David M. and Charles R. Plott (1979). "Economic Theory of Choice and the Preference Reversal Phenomenon." The American Economic Review 69(4), 623-638.

Griggs, Richard A. (1995). "The Effects of Rule Clarification, Decision Justification, and Selection Instruction on Wason's Abstract Selection Task." In S.E. Newstead and J. St. B.T. Evans (eds.) "Perspectives on Thinking and Reasoning", Lawrence Erlbaum Associates: Hove (UK).

Guala, F. (1999) “The Problem of External Validity (or 'Parallelism') in Experimental Economics," Social Science Information 38: 555-73.

Harless, David W. \& Colin F. Camerer (1994), "The Predictive Utility of Generalized Expected Utility Theories," Econometrica 62, 1251-1289.

Harrison, Glenn W. (1994), "Expected Utility Theory and the Experimentalists," Empirical Economics 19, 223-253. 
Harrison, Glenn W. (2006). "Making Choice Studies Incentive Compatible."

Forthcoming in Barbara Kanninen (ed.), Valuing Environmental Amenities Using Stated Choice Studies: A Common Sense Guide to Theory and Practice.

Harrison, Glenn W. (2007), "Hypothetical Bias over Uncertain Outcomes.” In John A.

List (Ed.), Using Experimental Methods in Environmental and Resource Economics, Elgar, Northampton, MA, forthcoming.

Harrison, Glenn W., Morten I. Lau, \& Melonie B. Williams (2002), “Estimating Individual Discount Rates in Denmark: A Field Experiment," American Economic Review $92,1606-1617$.

Harrison, Glenn W., Morten I. Lau, \& E. Elisabet Rutström (2007), “Estimating Risk Attitudes in Denmark: A Field Experiment," Scandinavian Journal of Economics 109, $341-368$.

Hertwig, Ralph, and Andreas Ortmann (2001). "Experimental Practices in Economics: A Methodological Challenge for Psychologists?” Behavioral and Brain Sciences 24, 383-451.

Hey, John D. \& Jinkwon Lee (2005), “Do Subjects Separate (or Are They

Sophisticated)?" Experimental Economics 8, 233-265.

Hoelter, Jon W. (1984). "Relative Effect of significant Others on Self-Evaluation." Social Psychology Quarterly, 47 (3), 255-262.

Hogarth, Robin M. (2005) "The Challenge of Representative Design in Psychology and Economics," Journal of Economic Methodology 12: 253-263.

Hogarth, Robin M. \& Hillel J. Einhorn (1990), "Venture Theory: A Model of Decision Weights," Management Science 36, 780-803.

Holt, Charles A. and Susan K. Laury (2002). "Risk Aversion and Incentive Effects." American Economic Review, 1644-1655.

Holtgraves, Thomas, and James Skeel (1992). "Cognitive Biases in Playing the Lottery: Estimating the Odds and Choosing the Numbers." Journal of Applied Social Psychology 22(12), 934

Horowitz, John K., and Kenneth E. McConnell (2002). “A Review of WTA/WTP Studies.” Journal of Environmental Economics and Management 44, 426-447. 
Huber, Oswald, and Gabriele Seiser (2001). "Accounting and Convincing: The Effect of Two Types of Justification on the Decision Process." Journal of Behavioral Decision Making 14, 69-85.

Johnson M.M.S. (1990). “Age differences in decision making: A process methodology for examining strategic information processing." Journal of Gerontology: Psychological Sciences 45, 75-78.

Kachelmeier, Steven J., and Mohamed Shehata (1992). "Examining Risk Preferences under High Monetary Incentives: Experimental Evidence from the People's Republic of China." American Economic Review 82(5), 1120-1141.

Kahneman, Daniel (2003a). “A Perspective on Judgment and Choice: Mapping Bounded Rationality." American Psychologist 58, 697-720.

Kahneman, Daniel (2003b). "Maps of Bounded Rationality: Psychology for Behavioral Economics." American Economic Review 93(5), 1449-1475.

Kahneman, Daniel, Jack L. Knetsch, and Richard H. Thaler (1991). „Anomalies: The Endowment Effect, Loss Aversion, and Status Quo Bias.” The Journal of Economic Perspectives 5(1), 193-206.

Keeney, Ralph L. \& Howard Raiffa (1976), “Decisions with Multiple Objectives.” Wiley, New York ( $2^{\text {nd }}$ edition 1993, Cambridge University Press, Cambridge, UK).

Keren, Gideon B. \& Léonie E.M. Gerritsen (1999), “On the Robustness and Possible Accounts of Ambiguity Aversion," Acta Psychologica 103, 149-172.

Kirkpatrick, Lee A., and Seymour Epstein (1992). “Cognitive-Experiential Self-Theory and Subjective Probability: Further Evidence for Two Conceptual Systems." Journal of Personality and Social Psychology 63(4), 534-544.

Kruglanski, Arie W. and Tallie Freund (1983). ,,The freezing and unfreezing of layinferences: Effects on impressional primacy, ethnic stereotyping, and numerical anchoring.” Journal of Experimental Social Psychology 19(5), 448-468.

Kühberger, Anton (1998). “The Influence of Framing on Risky Decisions: A Metaanalysis." Organizational Behavior and Human Decision Making Processes 75(1), 23-55. 
Kühberger, Anton, Michael Schulte-Mecklenberg, and Josef Perner (1999). „The Effects of Framing, Reflection, Probability, and Payoff on Risk Preference in Choice Tasks." Organizational Behavior and Human Decision Processes 78(3), 204-231.

Kühberger, Anton, Michael Schulte-Mecklenberg, and Josef Perner (2002). „Framing

Decisions: Hypothetical and Real." Organizational Behavior and Human Decision Processes 89(2), 1162-1175.

Kuhn, Thomas (1962). "The Structure of Scientific Revolutions."

Larrick, Richard P., Richard E. Nisbett, and James N. Morgan (1993). "Who Uses the Cost-Benefit Rules of Choice? Implications for the Normative Status of Microeconomic Theory." Organizational Behavior and Human Decision Processes 56, 331-347.

Lee, Jinkwon (2008), "The Effect of the Background Risk in a Simple Chance Improving Decision Model," The Journal of Risk and Uncertainty 36, 19-41.

Lerner, Jennifer S. and Philip E. Tetlock (1999). "Accounting for the Effects of Accountability." Psychological Bulletin 125, 255-275.

List, John A. (2004). "Neoclassical Theory versus Prospect Theory: Evidence from the Marketplace." Econometrica 72(2), 615-625.

List, John A. \& Craig A. Gallet (2001). "What Experimental Protocol Influence Disparaties between Actual and Hypothetical States Values? Evidence from a Meta-Analysis." Experimental and Resource Economics 20, 241-254.

Loewenstein, George (1999). "Experimental Economics from the Vantage Point of Behavioral Economics." Economic Journal 109, F25-F34.

Loewenstein, George (2000). "Emotions in Economic Theory and Economic Behavior." American Economic Review 90(2), 426-432.

Loewenstein, George F., Elke U. Weber, Christopher K. Hsee and Ned Welch (2001).

"Risk as Feelings." Psychological Bulletin 127(2), 267-286.

Lopes (1987). "Procedural Debiasing." Acta Psychologica 64

McCollum, Daniel W. (1997). Anchoring and adjustment in single-bounded, contingentvaluation question. American Journal of Agricultural Economics.

McElroy, Todd and John J. Seta (2003). "Framing Effects: An Analytic-Holitsic Perspective." Journal of Experimental Social Psychology 39, 610-617. 
McElroy, Todd and John J. Seta (2004). "On the Other Hand Am I Rational?

Hemispheric Activation and the Framing Effect.” Brain and Cognition 55, $572-580$.

Miller, Dale T., William Turnbull, and Cathy McFarland (1989). "When a Coincidence is Suspicious: The Role of Mental Simulation.” Journal of Personality and Social Psychology 57(4), 581-589.

Miller, Paul M., and N.S. Fagley (1991). "The Effects of Framing, Problem Variation, and Providing Rationale on Choice." Personality and Social Psychology Bulletin 17, 517-522.

Minor, Marshall W. (1970). "Experimenter-Expectancy Effect as a Function of Evaluation Apprehension.” Journal of Personality and Social Psychology 15(4), 326-332.

Myagkov, Mikhail G. \& Charles R. Plott (1997), "Exchange Economies and Loss Exposure: Experiments Exploring Prospect Theory and Competitive Equilibria in Market Environments," American Economic Review 87, 801-828.

Northcraft, Gregory B. , and Margaret A. Neale (1987). "Experts, amateurs, and real estate: An anchoring-and-adjustment perspective on property pricing decisions." Organizational Behavior and Human Decision Processes 39(1), 84-97.

Pacini, Rosemary, and Seymour Epstein (1999). "The Relation of Rational and Experiential Information Processing Styles to Personality, Basic Beliefs, and the Ratio-Bias Phenomenon." Journal of Personality and Social Psychology 76(6), 972-987.

Platt, Richard D., and Richard A. Griggs (1993). "Facilitation in the Abstract Selection Task: The Effects of Attentional and Instructional Factors.” Quarterly Journal of Experimental Psychology 46A(4), 591-613.

Plott, Charles R. and Kathryn Zeiler (2005a). "The Willingness to Pay - Willingness to Accept Gap, the "Endowment Effect", Subject Misconceptions and Experimental Procedures for Eliciting Evaluations.” American Economic Review 95(3), 530-545. Popper, Karl R. (1974). “Conjectures and Refutations.” London: Rutledge. 
Ratner, Rebecca K., and Barbara E. Kahn (2002). "The Impact of Private versus Public Consumption on Variety-Seeking Behavior.” Journal of Consumer Research 29, 246-257.

Read, Daniel (2005). “Monetary Incentives, What are They Good For?” Journal of Economic Methodology 12(2), 265-276.

Rosenthal, Robert (1991). "Meta-Analytic Procedures for Social Research.” Sage Publication, Newberry Park, CA.

Rottenstreich, Yuval, and Christopher K. Hsee (2001). "Money, Kisses, and Electric Shocks: On the Affective Psychology of Risk." Psychological Science 12(3), 185-190.

Sanfey, Alan G., George Loewenstein, Samuel M. McClure, and Jonathan D. Cohen (2006). "Neuroeconomics: Cross-Currents in Research on Decision Making." Trends in Cognitive Sciences 10(3), 108-116.

Scholten, Lotte, Daan van Knippenberg, Bernard A. Nijstad, Carsten K.W. De Dreu (2007). "Motivated Information Processing and Group Decision-Making: Effects of Process Accountability on Information Processing and Decision Quality." Journal of Experimental Social Psychology 43, 539-552.

Schwartz, Barry (1982), "Reinforcement-Induced Behavioral Stereotype: How not to Teach People to Discover Rules," Journal of Experimental Psychology: General $111,23-59$.

Sedikides, Constantine, Kenneth C. Herbst, Deletha P. Hardin, and Gregory J. Dardis (2002). "Accountability as a Deterrent to Self-Enhancement: The Search for Mechanisms.” Journal of Personality and Social Psychology 83(3), 592-605.

Shafir, Eldar, and Robyn A. LeBoeuf (2002). "Rationality." Annual Review of Psychology 53, 491-517.

Sieck, Winston, and J. Frank Yates (1997). "Exposition Effects on Decision Making: Choice and Confidence in Choice." Organizational Behavior and Human Decision Processes 70(3), 207-219.

Siegel-Jacobs, Karen and J. Frank Yates (1996). „Effect of Procedural Accountability and Outcome Accountability on Judgment Quality.” Organizational Behavior and Human Decision Processes 65(1), 1-17. 
Simmons, Joseph P., Robyn A. LeBoef, and Leif D. Nelson (2006). "When Motivation Increases Adjustment Away From Provided Anchors.” Working Paper Simon, Herbert A. (1955). "A Behavioral Model of Rational Choice.” Quarterly Journal of Economics 69, 99-118.

Simonson, Itamar (1989). Choice Based on Reason: the Case of Attraction and Compromise Effect. The Journal of Consumer Research 16(2), pp. 158-174.

Simonson, Itamar and Peter Nye (1992). "The Effect of Accountability and Susceptibility on Decision Errors." Organizational Behavior and Human Decision Processes 51, 416-446.

Simonson, Itamar, and Barry M. Straw (1992). "Deescalation Strategies: A Comparision of Techniques for Reducing Commitment to Losing Courses of Action." Journal of Applied Psychology 77(4), 419-426.

Sloman, Steven A. (2002). "Two Systems of Reasoning." In "Heuristics and Biases: The Psychology of Intuitive Judgment", T. Gilovich and D. Griffin eds., 379-396.

Slovic, Paul (1969), "Differential Effects of Real versus Hypothetical Payoffs on Choices among Gambles," Journal of Experimental Psychology 80, 434-437.

Slovic, Paul (1995). The Construction of Preference. American Psychologist, 364-371.

Smith, Eliot R. and Jamie DeCoster (2000). "Dual-Process Models in Social and Cognitive Psychology: Conceptual Integration and Links to Underlying Memory Systems." Personality and Social Psychology Review 4(2), 108-131.

Smith, Vernon L. (1982). "Microeconomic Systems as an Experimental Science." American Economic Review 72, 923-955.

Smith, Vernon L. and James M. Walker (1993). "Monetary Reward and Decision Cost in Experimental Economics.” Economic Inquiry 31(2), 245-261.

Strack, F., \& Mussweiler, T. (1997). "Explaining the enigmatic anchoring effect: Mechanisms of selective accessibility." Journal of Personality and Social Psychology, 73, 437-446.

Starmer, Chris \& Robert Sugden (1991), "Does the Random-Lottery Incentive System Elicit True Preferences? An Experimental Investigation," American Economic Review 81, 971-978. 
Staw, Barry M., and Jerry Ross (1978). "Commitment to a Policy Decision: A MultiTheoretical Perspective.” Administrative Science Quarterly 23(1), 40-64.

Sunghan, Kim, David Goldstein, Lynn Hasher, and Rose T. Zacks (2005). "Framing Effects in Younger and Older Adults." Journal of Gerontological B Psychol Sci Soc Sci. 60, 215-218

Takemura, Kazuhisa (1993). "The effect of decision frame and decision justification on risky choice.” Japanese Psychological Research 35, 36-40.

Takemura, Kazuhisa (1994). "Influence of Elaboration on the Framing of Decision." Journal of Psychology 128(1), 33.

Tetlock, Philip E. (1983). “Accountability and Complexity of Thought.” Journal of Personality and Social Psychology 45 (1), 74-83.

Tetlock, Philip E. (1985). “Accountability: A Social Check on the Fundamental Attribution Error.” Social Psychological Quarterly 48(3), 227-236.

Tetlock, Philip E. and Richard Boettger (1989). “Accountability: A Social Magnifier of the Dilution Effect." Journal of Personality and Social Psychology 57 (3), 388-398.

Thaler, Richard (1980). “Toward a Positive Theory of Consumer Choice.” Journal of Economic Behavior and Organization 1, 39-60.

Thaler, Richard H. (1987), "The Psychology and Economics Conference Handbook: Comments on Simon, on Einhorn and Hogarth, and on Tversky and Kahneman." In Robin M. Hogarth \& Melvin W. Reder (eds.), "Rational Choice: The Contrast between Economics and Psychology," 95-100, University of Chicago Press.

Trautmann, Stefan T., Ferdinand M. Vieider, and Peter P. Wakker (2008a). „Causes of Ambiguity Aversion: Known versus Unknown Preferences.” Journal of Risk and Uncertainty, forthcoming.

Trautmann, Stefan T., Ferdinand M. Vieider, and Peter P. Wakker (2008b). „Preference Reversals to Explain Ambiguity Aversion.” Working Paper, Erasmus University Rotterdam.

Tversky, Amos \& Daniel Kahneman (1974). “Judgment under uncertainty: Heuristics and biases." Science 185, 1124-1130. 
Tversky, Amos and Daniel Kahneman (1986). "Rational Choice and the Framing of Decisions." The Journal of Business 59(4), S251-S278.

Tversky, Amos and Daniel Kahneman (2002). "Extentional versus Intuitive Reasoning: the Conjunction Fallacy in Probability Judgment." In " Heuristics and Biases, the Psychology of Intuitive Judgment”, Cambridge University Press.

Vieider, Ferdinand M. (2007). "Accountability and Risk Attitude: Probability Weighting, Uitlity Curvature, and Loss Aversion.” Working Paper, Erasmus University Rotterdam.

Vieider, Ferdinand M. And Philip E. Tetlock (2008b). "Accountability and Incentives: A Meta-Study." Working Paper.

Wansink, Brian, Robert J. Kent, and Stephen J. Hoch (1998). "An Anchoring and Adjustment Model of Purchase Quantity Decisions.” Journal of Marketing Research 35(1), 71-81.

Watson, David and Ronald Friend (1969). "Measurement of Social-Evaluative Anxiety." Journal of Consulting and Clinical Psychology 33(4), 448-457.

Wilcox, Nathaniel D. (1993). "Lottery Choice: Incentives, Complexity, and Decision Time.” Economic Journal 103(421), 1392-1417.

Wilson, Timothy D., Nancy Brekke, Christopher E. Houston, and Kathryn M. Etling (1996). "A New Look at Anchoring Effects: Basic Anchoring and its Antecedents." Journal of Experimental Psychology: General 125(4), 387-402.

Wilson, Timothy D., and Jonathan W. Schooler (1991). "Thinking Too Much: Introspection Can Reduce the Quality of Preferences and Decisions." Journal of Personality and Social Psychology 60(2), 181-192.

Wiseman, David B., and Irwin P. Levin (1996). "Comparing Risky Decision Making Under Conditions of Real and Hypothetical Consequences." Organizational Behavio and Human Decision Processes 66(3), 241-250.

Wright, William F., and Urton Anderson (1989). "Effects of Situation Familiarity and Financial Incentives on Use of the Anchoring and Adjustment Heuristic for Probability Assessment." Organizational Behavior and Human Decision Processes $44,68-82$. 
Yadov, M. (1994). "How Buyers Evaluate Product Bundles: A Model of Anchoring and Adjustment." Journal of Consumer Research. 